\title{
A delimitação das terras da câmara de Vila do Carmo/Mariana: aspectos de dinâmica e materialidade da posse de terras na América Portuguesa em 1719 e 1752
}

\section{The land delimitation of the Council of Vila do Carmo/Mariana: dynamic and materiality of land ownership in Portuguese America in 1719 and 1752}

Tercio Voltani Veloso*

\begin{abstract}
Resumo
O presente artigo busca demonstrar as semelhanças e diferenças entre dois processos de demarcação do patrimônio da câmara de Vila do Carmo/Mariana no século XVIII, em 1719 e 1752. Através da análise dessas demarcações, pretende-se elucidar aspectos que permeiam a dinâmica e a materialidade da posse das terras ocupadas pelos portugueses no interior da América. Dessa forma, será possível perceber os conflitos e ritos possessórios que estiveram presentes na consolidação da ocupação lusitana na área das jazidas auríferas.
\end{abstract}

Palavras-chave: Minas Gerais. Mariana. Sesmaria. Câmara.

\begin{abstract}
This article tries to demonstrate the similarities and differences between two processes of demarcation of the Council of Vila do Carmo/Mariana in the Eighteenth Century, in 1719 and 1752. Through the analysis of these demarcations, we intend to elucidate aspects underlying the dynamics and the materiality of the possession of lands occupied by the Portuguese in the hinterland of America. Thus it will be possible to understand the conflicts and rites os ownership that were present in the consolidation of Portuguese occupation in the area of gold deposits.
\end{abstract}

Keywords: Minas Gerais. Mariana. Sesmaria. Council.

\footnotetext{
* Mestrando em História no Programa de Pós-Graduação da Universidade Federal de Ouro Preto. E-mail: terciovelosotp@hotmail.com
} 
A instalação de vilas, e a consequente fundação das câmaras, representou a forma de administração implementada pelo governo lusitano em nível local em todo o Império ultramarino. Para os portugueses, era uma forma de garantir certa estabilidade no governo de terras longínquas, ainda que a custo de uma grande autonomia por parte das câmaras. ${ }^{1}$

Além da função administrativa das relações políticas e econômicas de uma localidade, as câmaras recebiam um patrimônio fundiário, uma gleba de terra que poderia ser arrendada a particulares, mediante o pagamento de um imposto anual conhecido como foro: os moradores eram os foreiros e as parcelas de terras eram postas em aforamento aos moradores que tivessem interesse. ${ }^{2}$

A doação de terras para a composição dos bens do concelho, ou da Câmara, foi uma prática nos domínios lusitanos desde a reconquista da península ibérica da mão dos mouros. Grupos que se formavam localmente, aliados ao rei de Portugal e a fé católica, recebiam do monarca - ou de um senhorio eclesiástico - certos poderes autônomos e a administração de uma gleba de terra, uma sesmaria que formava o patrimônio fundiário dessas municipalidades. ${ }^{3}$

A estrutura básica desse patrimônio seria então dividida nas terras públicas destinadas a pastagens e plantações públicas - os baldios - e outra parcela podia ser retalhada e concedida à população sob a forma dos aforamentos, situação essa que se repetiu em todo o ultramar lusitano, inclusive na ocupação do território interior do Brasil.

Na ocupação do território mineiro nos inícios do século XVIII, sendo as vilas criadas em localidades onde já existia alguma ocupação, a concessão desse patrimônio às câmaras acabava se sobrepondo a patrimônios

\footnotetext{
${ }^{1}$ Cf. BOXER, Charles Ralph. O Império Ultramarino Português (1415-1825). Tradução Inês Silva. Lisboa: Edições 70, 1969; BICALHO, Maria Fernanda. "As câmaras ultramarinas e o governo do Império". In: FRAGOSO, João, BICALHO, Maria Fernanda \& GOUVEA, Maria de Fátima (orgs.). O Antigo Regime nos trópicos: a dinâmica imperial portuguesa (séculos XVI-XVIII). Rio de Janeiro, Civilização Brasileira, 2001; GOUVEA, Maria de Fátima. "O desaguadouro das tensões". In: BICALHO, Maria Fernanda \& FERLINI, Vera Lúcia Amaral (orgs.). Modos de governar: idéias e práticas políticas no império português - séculos XVIXIX. São Paulo: Alameda, 2005.

2 “A prática dos aforamentos era comum no reino desde o século XII e constituía na vinculação de um bem
a um concessionário mediante o pagamento periódico de um valor previsto em contrato. Tais contratos
tinham validade perpétua e muitas vezes permitiam negociações de compra, venda, arrendamentos, en-
tre outros e ficavam como herança para as gerações futuras, constituindo, nas palavras de Paulo Merea,
em "propriedades imperfeitas"”. In: MAIA, Thalita. "Terras cariocas: aforamentos do século XVIII na his-
toriografia da cidade do Rio de Janeiro". Anais do XIV Encontro Regional ANPUH-Rio: História e patrimônio.
2010. p. 3 .
} ${ }^{3}$ Ibidem. 
particulares. ${ }^{4}$ Esses proprietários - particulares individuais ou entidades coletivas - nem sempre reconheciam de bom grado o direito das câmaras sobre as terras, marcando uma série de conflitos em torno da delimitação e, sobretudo, do reconhecimento do patrimônio da câmara. ${ }^{5}$

Algumas informações sobre o processo de definição do patrimônio fundiário de Vila do Carmo/Mariana são passíveis de serem tateadas cruzando a historiografia e a documentação que dispomos. Segundo Claudia Damasceno Fonseca, o processo de formação e confirmação do patrimônio fundiário da câmara de Vila do Carmo foi bastante extenso e tumultuado, sobretudo com relação aos aforamentos. ${ }^{6}$ As delongas começaram ainda na primeira tentativa de demarcação feita por Dom Brás Baltazar da Silveira e arrastaram até a segunda metade do século XVIII, como veremos.

A constituição do patrimônio pertencente à câmara de Vila do Carmo/ Mariana exigiu o empenho de diversos oficiais régios ao longo da primeira metade do século XVIII, muito pelas transformações ocorridas na disposição de seu espaço urbano e pelo próprio dinamismo da ocupação do território minerador. Tem-se notícia de dois processos de demarcação das terras da sesmaria de Mariana, em $1719^{7}$ e $1752 .{ }^{8}$ A investigação dessas demarcações, e dos trâmites delas decorrentes, pode mostrar os movimentos do alcance da jurisdição da câmara e a complexificação da ocupação do espaço.

Algumas cartas encontradas entre as fontes manuscritas da época mostram as disputas entre a câmara e os moradores. Lá também a principal questão dizia respeito à sobreposição dessa demarcação sobre as terras de moradores que se diziam primeiros povoadores, ocupantes daquelas terras antes mesmo da fundação da vila. Essas querelas podem ser apontadas como causa da demora na demarcação do patrimônio da câmara de Vila do Carmo,

\footnotetext{
${ }^{4}$ Atendo-se às cidades mineiras, Murilo Marx observou que a gestão das terras ditas "públicas" era um foco de conflito entre os presumidos detentores da terra, ou seja, a igreja e a câmara. Assim, na pesquisa sobre a estrutura fundiária, podemos tatear aspectos desse conflito entre as instâncias temporal e espiritual na gestão das terras concedidas aos moradores. Cf. MARX, Murilo. Cidade no Brasil: terra de quem? São Paulo: Edusp/Fapesp, 1991.

5 "Uma vez que as vilas não eram criadas exnihilo, mas nos arraiais preexistentes, os patrimônios municipais acabavam se sobrepondo a outros tipos de concessões, mais antigas: as sesmarias dos fazendeiros, as datas minerais ou os patrimônios das capelas de irmandades e matrizes." FONSECA, Claudia Damasceno. Arraiais e Vilas d'El rei. Espaço e poder nas Minas setecentistas. (trad: Maria Juliana Gamboni Teixeira e Claudia Damasceno Fonseca). Belo Horizonte: Ed. UFMG, 2011, p. 462.

${ }^{6}$ FONSECA, op. cit., p. 460-499.

${ }^{7}$ Arquivo da Casa Setecentista de Mariana (ACSM), $1^{\circ}$ Livro do Senado da câmara da Vila do Carmo (17111720), f. 201v-202v.

${ }^{8}$ Arquivo Histórico da câmara Municipal de Mariana. (AHCMM), Códice 417. f. 18-35.
} 
erigida em 1711.

.A primeira concessão do patrimônio da câmara feita pelo rei aconteceu após um requerimento dos camaristas de Vila do Carmo de 1715, onde se queixavam da falta de rendimentos do senado para as obras e demais obrigações públicas. Assim, solicitavam ao rei que "concedesse uma légua de realengo ou sesmaria com poder de aforar as terras dela para assim se remediarem as necessidades do preciso". 9

Em 24 de Outubro de 1716, o então governador de São Paulo e Minas, Dom Brás Baltazar da Silveira confirmava a doação real para a composição do patrimônio da câmara, atendendo às conveniências que se impunham para o maior aumento da vila, e estabelecia também o método a ser empregado na demarcação.

(...) Por quanto Sua Majestade que Deus Guarde me ordenou desse por sesmaria à câmara desta Leal Vila de Nossa Senhora do Carmo terras competentes para possuírem; e atendendo a que he muy conveniente que a dita câmara tenha terras para mayor aumento desta dita Vila, hei por bem de fazer mercê em nome de Sua Majestade a câmara dela de hua legoa de terras em quadra, a qual fará pião no Pelourinho desta Vila, correndo para todas as partes na distância de meia légua, das quais terras terá a câmara o direito senhorio, usando delas na forma da ordem do dito senhor. ${ }^{10}$

As desavenças entre os moradores e a câmara da Vila do Carmo surgiram antes mesmo de ser feita a demarcação das terras. Ainda em 1716, os oficiais da câmara enviaram uma carta ao rei propondo "o obstáculo que se lhe ofereceu, ao quererem tomar posse da sesmaria, que o dito senhor lhe fez mercê". ${ }^{11}$ Nela, o rei tomava notícia de uma petição assinada por "alguns moradores situados na distância sobredita (...) dizendo lhes prejudicava a dita sesmaria pela sua posse ser primeiro que a vila." ${ }^{12}$ E que a câmara encontrava-se, então, impugnada da posse pelos moradores, ainda que alguns deles quisessem ser foreiros da câmara, muito em virtude dos matos que estavam ainda por cultivar.

\footnotetext{
9 "Vos faço saber a vos oficiais da câmara da Vila Real de Nossa Senhora do Carmo que se viu a vossa carta do $1^{\circ}$ de Dezembro do ano passado (1715) em que vos queixais achar-se esse Senado com poucos rendimentos para as obras de que careceis, como he a casa da câmara e Cadeia e mais festas reais de obrigação, e pontes, pedindo me vos concedesse hua légua de realengo ou sesmaria com poder de aforar as terras della para assim se remediarem as necessidades do precizo." Arquivo da Casa Setecentista de Mariana (ACSM), $1^{\circ}$ Livro da câmara Municipal de Mariana (1711-1720), f. 72v.

${ }^{10}$ Idem, f. $89 \mathrm{v}$.

${ }^{11}$ Idem, f. $96 \mathrm{v}$.

${ }^{12}$ Idem.
} 
Essa carta mostra o conhecimento da prática de que os foreiros podiam ter acesso aos matos e terras que se encontravam baldios. Esses baldios ficavam disponíveis para o uso ou como pastagem ou para a retirada de lenhas a serem utilizadas nas casas e mais serviços que os moradores possuíam. Além disso, representavam a probabilidade de ainda se encontrar algum rendimento aurífero, quando se tratava das proximidades de determinado serviço de minerar de maior monta ou de lavras já abandonadas. ${ }^{13}$

O rei, todavia, ciente dos rebuliços causados em toda a extensão do Império pelas notícias do manifesto do ouro, afirmava que "requerendo vários nesta ocasião várias datas de terra nessas mesmas, ele nas não houve por bem por mandar lhes deferir." 14 Despachada de Lisboa em 1718, essa negativa do rei em confirmar a propriedade primeira dos habitantes e, em consequência, isentá-los do pagamento de foros - diferentemente da conduta do governador Dom Brás Baltazar da Silveira que procurava prevenir as demarcações sobre as terras de homens de grande cabedal - pode ser tida como uma preferência dada pelo monarca à constituição do patrimônio da vila frente aos particulares.

Por fim, em meados de 1719, é registrada a carta definitiva do rei para se proceder a referida demarcação, ficando a câmara na "diligência de logo demarcar a dita légua de terra na forma da real mercê concedida por Vossa Real Majestade." 15 Os camaristas recorreram, então, ao secretário de Estado André Lopes de Laura, explicitando que,

Sua Majestade que Deus Guarde que foi servido escrever a esta câmara confirmando lhe a mercê de huma légua de terra de sesmaria para patrimônio della, nos ordena o mandemos confirmar por Sua Real Pessoa e como nessa Corte não temos pessoa de mais zelo e honras que a esta câmara tenha feita que Vossa Senhoria nos motiva estas razões, a valer nos desse patrocínio para que se digne mandar apresentar a dita sesmaria a Sua Real Majestade para a confirmar na forma de sua ordem. ${ }^{16}$

\footnotetext{
${ }^{13}$ A respeito das "faisqueiras" de ouro em terras contingentes a grandes serviços minerais e em lavras abandonadas, ver REZENDE, Dejanira Ferreira de."Arraia-miúda" nos morros das Minas: conflitos sociais na Vila do Carmo, década de 1710. Monografia de Bacharelado. UFOP/DEHIS, 2010.

${ }^{14}$ Não se tem notícias do original desse documento, o qual não está anexado aos demais papéis no designado $1^{\circ}$ Livro da câmara Municipal de Mariana (1711-1720). Utilizo uma cópia que se encontra no primeiro códice dos Livros do Tombo de 1752, feita a mando do ouvidor Costa Matoso. Registro de hua carta de Sua Majestade escrita a câmara desta Cidade Mariana e se acha no Livro primeiro do registro a folhas [ ]. Arquivo Histórico da câmara Municipal de Mariana. (AHCMM), Códice 417, f. 7v.

${ }^{15}$ ACSM, f. 170v.

${ }^{16}$ Idem, f. $172 v$.
} 


\section{A primeira demarcação da sesmaria em 1719}

Cumprindo as determinações reais, em novembro de 1719, todos os representantes que comandavam a câmara na Vila do Carmo estavam reunidos junto ao pelourinho da câmara; seus homens-bons, os vereadores, deram início ao primeiro processo de demarcação da sesmaria pertencente à câmara da Vila do Carmo. Seguindo as demandas reais de demarcar uma légua em quadra, na distância de meia légua para todas as partes a partir do Pelourinho, a primeira dificuldade enfrentada foi a falta de um "piloto que seguissem o rumo por agulhão"17 na vila.

$\mathrm{Na}$ falta deste, era necessário, então, chamar uma pessoa com conhecimento suficiente dos ditos rumos para que a medição fosse feita. Não sabemos quem teria sido o escolhido para tal função pelo Senado da câmara, contudo, o trabalho prosseguiu, mostrando que algum daqueles homens tenha sido visto pelos vereadores como capaz para prosseguir a delimitação dos rumos que a medição deveria tomar. Outro equipamento utilizado pelos oficiais da câmara foi uma corda, possivelmente de 50 braças de comprimento (aproximadamente 120 metros) que deveria ser usada para o computo das distâncias medidas.

Principiada a medição em 13 de novembro de 1719, os oficiais tomaram primeiro o rumo de noroeste "até ajustar mil e quinhentas braças distância completa de meia légua, (...) sendo esta finda no sítio do Sargento-mor Antônio de Faria Pimentel donde tinha o sitio o forno de coser telha", 18 estabelecendo ali o primeiro marco. No dia seguinte, os oficiais tomaram o rumo de nordeste pela "estrada geral de Ribeirão Abaixo" a partir do Pelourinho, indo completar as mil e quinhentas braças "no córrego que entra o sitio de Paschoal da Gama e o sitio do Capitão Pedro Rodrigues e Sanches no caminho velho que se segue pelo dito ribeirão abaixo principio do Morro Grande chamado por [antinomazio] ${ }^{19}$ de Domingos Velho", estabelecendo o segundo marco da sesmaria. Ali, mandaram "fincar [marco da divisa real] no barranco do dito córrego, da outra parte direita da estrada” ${ }^{20}$ e, por já ser tarde, a medição continuaria no dia seguinte.

\footnotetext{
${ }^{17}$ Idem, f. $201 \mathrm{~V}$.

${ }^{18}$ Idem, f. 202.

${ }^{19}$ Segundo o dicionário de Bluteau, “antinomasia” é "uma figura própria, com a qual em lugar do nome próprio, pomos outro por excelência e com louvor.” Uma interpretação possível é que o morro era conhecido como morro de Domingos Velho. Entretanto, é perceptível que não há clareza na nomeação de tal marco geográfico. BLUTEAU, Raphael. Vocabulário portuguez e latino. Coimbra: Colégio das artes da Companhia de Jezus, 1712. (edição fac-símile em CR-ROM).Verbete antinomasia, 1ํVolume, p. 411.

${ }^{20}$ ACSM, f. 202.
} 
No terceiro dia de trabalho, o rumo tomado foi o de "[sudeste pelo agulhão] (...) encaminhando para a estrada chamada Itacolomim (sic)" ${ }^{21} \mathrm{~A}$ meia légua fora alcançada na altura do "sítio de Gabriel Pereira de [?] ao fim de hum serro íngreme muito alto que se acha no dito lugar", ${ }^{22}$ onde na parte mais alta os oficiais mandaram colocar o terceiro marco. Por fim, o quarto rumo tomado foi de "sudueste pelo agulhão, finda esta em mil e quinhentas braças, distância de meia légua, que se completou no arraial chamado da Passaje (sic), estrada geral da Vila Rica no fim da última casa e morador do dito arraial", ${ }^{23}$ onde, assim como nos outros três pontos, mandou-se colocar o quarto e último marco.

Acompanhando as demarcações, a comitiva da câmara tinha também os responsáveis por fazer os ritos possessórios posteriores à demarcação da sesmaria. Esses rituais consistiam basicamente em "apregoar a dita posse", função do porteiro do Senado, que deveria lançar três vezes em voz clara e alta para saber se alguma pessoa poderia apresentar oposição para tal posse que estava sendo tomada. ${ }^{24}$ Além disso, a câmara mandava confeccionar marcos reais com inscrição REY para delimitar a medição feita. Em cada um dos pontos onde a medição completava a meia légua, um desses marcos era estabelecido e o escrivão da câmara professava o ato possessório de "cortar árvores e ramos e cavar nas terras lançando-as ao ar". ${ }^{25}$

Entre os aspectos dessa medição feita ainda no início do estabelecimento da povoação nas Minas Gerais, pode-se ressaltar alguns pontos que destacam a incipiência da ocupação e da formação dos aglomerados urbanos, tais como a falta de marcos perenes e a facilidade com que o processo de delimitação da légua em quadra foi feita.

A falta de marcos perenes no espaço a ser delimitado pode ser percebida no fato de que as medições sempre se encerravam nas proximidades de um sítio de certo morador, de forma que uma troca de propriedade já torna-

\footnotetext{
${ }^{21}$ Idem, f. 202-202v.

${ }^{22}$ Idem, f. $202 \mathrm{v}$.

${ }^{23}$ Idem.

${ }^{24}$ Essa passagem é significativa: “a vista dos tais documentos estarem jurídicos em forma pelo Porteiro do Auditório João Barbosa apregoando a dita posse, o que assim fiz apregoando primeira segunda e terceira vez se via algua pessoa que dicesse alguns embargos a não se dar posse da dita carta de sesmaria aos ditos senhores viesse com eles para se lhe deferir como fosse justamente sem que houvesse impedimento algum, mandou o Procurador do Senado fazer Marco Real, e marcar a paragem, donde a vista de não haver impedimento algum, [começaram por entre postas] pessoas dos oficiais de justiça [alcaide] escrivão." ACSM, f. 202v.

${ }^{25}$ Idem, f. 202-202v.
} 
ria mais difícil de localizar as balizas da medição feita pela câmara. Mesmo que fosse comum aos portugueses em suas cidades coloniais dar nomes aos logradouros de acordo ou com algum morador mais ilustre ou da atividade praticada nas proximidades, costume esse que dava bastante mobilidade aos nomes das ruas e travessas das cidades coloniais em geral, o uso dessas propriedades de fulano de tal como marcos revela a inesxistência, por exemplo, de uma capela ou mesmo um ribeirão a que todos já conhecessem a denominação - e que pudesse fazer a marcação de forma mais duradoura. Além disso, pode-se aventar a hipótese de que durante o passar dos anos os primeiros marcos que a câmara mandou fazer e colocar nas demarcações tivessem se deteriorado ou mesmo desaparecido, o que pode então ter contribuído para colocar sobre dúvida a extensão do patrimônio da câmara. ${ }^{26}$

Em todas as direções em que partiram - noroeste, nordeste, sudeste e sudoeste - os oficiais da câmara não citam sequer um desvio que tenham feito por ocasião de uma casa, uma igreja ou um quintal murado que fosse obstáculo para a medição. Assim, sem empecilhos, de forma que rapidamente atingiam as mil e quinhentas braças e colocavam o marco, os oficiais conseguiram fazer a medição sem encontrar obstáculos que impedissem ou dificultassem o prosseguimento da medição, algo que, como veremos adiante, não se mostrará tão fácil e simples para a equipe do ouvidor Costa Matoso.

As tensões acerca dessa demarcação aumentaram quando as mudanças ocasionadas pelas enchentes do Ribeirão do Carmo, que levaram ao deslocamento do centro da localidade para as terras mais altas e afastadas do rio antes ocupadas pelos pastos do Quartel dos Dragões, trouxeram também o translado do Pelourinho para a nova praça que se formava. Como vimos, o Pelourinho constituía o centro geográfico das medições da légua em quadra pertencente à câmara e, com sua mudança de local, alterava-se também a medição que precisaria, em virtude das querelas entre moradores e a câmara em torno dos foros, ser refeita.

As dúvidas sobre a demarcação original fizeram os camaristas da Vila do Carmo, já na condição de cidade de Mariana, solicitarem junto ao governo da capitania a presença de um juiz para fazer o tombo da sesmaria e colocar em devida forma a cobrança dos foros da agora cidade episcopal. ${ }^{27}$

\footnotetext{
${ }^{26}$ Cf. FONSECA, op. cit.

27 “Em meados do século XVIII, alguns habitantes ainda se recusavam a reconhecer que seus terrenos faziam parte do patrimônio municipal e que deviam, portanto, pagar foros anuais à câmara." FONSECA, op. cit., p. 473.
} 


\section{Os Livros do Tombo e a (re)demarcação de sesmaria em 1752}

Os trâmites que envolveram o processo de demarcação da sesmaria feito na metade do século XVIII são passíveis de serem captados nos documentos compilados pelo ouvidor Caetano da Costa Matoso na abertura dos Livros do Tombo de 1752. De certo modo, é possível perceber de antemão que à medida que a estrutura social da povoação adquiriu ares mais complexos, o mesmo também ocorreu com a sua estrutura física.

Dentre esses documentos estão cartas régias de confirmação da sesmaria, arbítrios reais sobre a ocupação do espaço na Vila do Carmo e uma cópia do processo de demarcação da sesmaria de 1719, além da minúcia do processo da nova demarcação, feita em 1752. Essa compilação e cópias de documentos requeridas pelo então juiz do Tombo, o ouvidor Costa Mattoso, mostra bem qual era a finalidade do trabalho empreendido para "tombar" a sesmaria da cidade: confirmar a autoridade da câmara sobre sua gleba de terra.

No dia 18 de janeiro de 1752, o ouvidor Costa Matoso, nas obrigações de juiz do tombo, principiaria a medição da légua em quadra pertencente à câmara. O marco central, assim como em 1719, seria o Pelourinho da cidade, mas como esse havia sido transferido para a recém demarcada nova praça, na região dos quartéis, os marcos limítrofes da sesmaria foram alterados. Assim,

posto o agulhão no Pelourinho da mesma praça mandou o dito Doutor Juiz do
Tombo apregoar aos [hereos] e incertos contraditores da Sesmaria concedida a
câmara da mesma cidade pelo porteiro Joseph Luiz nomeado para este Tombo
e por não haver que o contradicesse (sic) ou impugnasse mandou aos ditos
louvados e medidores principiassem a medição na distância de meia légua
pelo rumo do agulhão para a parte que achassem com menos embaraço. ${ }^{28}$

Optou-se assim por seguir o "rumo de nor-noroeste correndo rumo direito para o Morro de Santa Anna." ${ }^{29}$ Contudo, já nessa primeira medição, foi possível perceber o obstáculo que o crescimento da cidade representaria para o trabalho do ouvidor:, algumas casas que cercavam a praça impediram que os medidores seguissem na direção escolhida, obrigando-os a descerem pela rua, que apontava em rumo norte, até as margens do Ribeirão do Carmo,

a porem se fora das casas para melhor se seguir a dita medição de nornoroeste, abatendo se [ao depoes] na dita medição tudo o que se entendesse

\footnotetext{
${ }^{28}$ AHCMM, f. 18.

${ }^{29}$ Idem.
} 
tinha acrescido para o rumo do norte em forma que a dita medição podese correr em linha reta e sem diminuição ou aumento algum para o dito rumo de nor-noroeste. ${ }^{30}$

Nas margens do ribeirão a medição somava 100 braças e, a partir dali, os oficiais atravessaram rio chegando a Rua dos Monsus. Para seguir na direção do Morro de Sant'Anna, os medidores entraram pelos quintais de Pedro de Carvalho e, saindo novamente na rua, correram morro acima até a parte

detrás das casas que novamente estava fazendo Brás Alves Martins, em hum desbarrancado do mesmo morro até onde se contava oito cordas que a razão de cinquenta braças cada huma completavam o numero de quatrocentas braças. ${ }^{31}$

Do alto desse morro, os oficiais passaram a examinar os desvios que tinham feito afim de estimar uma linha reta até o Pelourinho. Todavia, os instrumentos disponíveis para tal aferição não eram nada mais do que a percepção dos próprios oficiais e do ouvidor. Desse exame ocular, observaram que pela

linha reta tomada ao Pelourinho e a volta que tomou a mesma medição para a parte do Norte para se poder fazer com comodidade acharam por estimação que deviam abater cento e cinqüenta braças, que demais lhes parecia se tinham medido pela volta que fez a dita medição vindo assim a ficar a dita medição até este sítio de cinco cordas somente, que fazem o número de duzentas e cinquenta braças. ${ }^{32}$

Feitos os devidos abatimentos e prosseguindo a medição pelo morro de Sant'Anna, chegaram a um ponto onde se "achava huma cruz grande com hum retábulo das Almas e junto a qual se completavam dezenove cordas que fazem o [computo] de novecentas e cinqüenta braças." 33 Observando novamente os desvios, os medidores abateram mais duas cordas, ou 100 braças, ficando até ali somadas 850 braças de distância ao Pelourinho.

Desse ponto a medição seguiu até dentro do arraial de Sant'Anna, somando junto as casas de João Gaspar o total de 1200 braças, ou 24 cordas. No dia seguinte, as 300 braças restantes seriam medidas, completando-se

\footnotetext{
${ }^{30}$ Idem.

${ }^{31}$ Idem.

${ }^{32}$ Idem, f. $18 v-19$.

${ }^{33}$ Idem, f. $19 \mathrm{v}$.
} 
junto a hum rego de água que na mesma paragem (...) o número de mil e quinhentas braças chegando a última corda na lombada que faz o dito Morro de Santa Anna virando para o fundão em hum sitio junto ao mesmo rego. ${ }^{34}$

Partindo a medição para a segunda determinação da meia légua, a equipe do ouvidor escolheu sair "para a parte do Tapanhuacanga e caminho que vai para os Camargos seguindo o rumo do Norte com pouca diferença para a parte da quarta, do Noroeste." ${ }^{35}$ Então, saíram da praça pela rua que ia dar na praia do Ribeirão e o atravessaram, assim como fizeram na parte anterior da medição. Dali, os medidores avançaram para os Monsus,

seguindo a estrada buscando sempre a borda do rio por se fazer por ela com mais comodidade a dita medição até que desviando-se do mesmo e buscando mais o rumo que levavam seguiram para a parte da rossa e casas do Alferes Francisco da Mota del [?], junto as quais passou a dita medição atravessando ali o córrego que vem da parte do caminho de Antonio Pereira subiu pelo morro acima a buscar o mesmo Tapanhuacanga e chegando ao mais alto daquele morro por aquela parte ali mesmo completou a medição o número de vinte e três cordas. ${ }^{36}$

Na parte mais alta do morro, os oficiais buscaram fazer nova estimativa da diferença da medição, abateram duas cordas e meia, ficando em 20 cordas e meia naquele ponto. Seguindo a medição para sua última parte

pelo dito morro acima e rumo que levava com pouca diferença do Norte se foi buscando o dito caminho de Tapanhuacanga e por ele acima se completou a medição das trinta cordas feito outro abatimento de corda e meia por atenção ao que de mais se tinha desviado do rumo a dita medição e complentandose em hum sítio de Tapanhuacanga que se achava junto a estrada da parte esquerda seguindo para os Camargos. ${ }^{37}$

Voltando novamente ao Pelourinho, iniciaram a terceira parte da medição para o rumo do Nordeste, buscando o caminho que levava ao arraial de São Sebastião. Mas também para este rumo, a exemplo do que aconteceu no rumo tomado para o Morro de Sant'Anna, muitas casas e os declives do terreno tornavam dificultosa a medição. Por isso, optaram por tomar a direção da

\footnotetext{
${ }^{34}$ Idem, f. 20v.

${ }^{35}$ Idem, f. $21 \mathrm{v}$.

${ }^{36}$ Idem, f. 22.

${ }^{37}$ Idem, f. 22v.
} 
estrada junto a Capela de Santa Anna e seguindo sempre a mesma se passou a cachoeira que se acha na estrada e se foi seguindo o mesmo caminho até chegar a um alto em que se acha uma Cruz a que chamam das Almas junto a qual completou a medição quinze cordas..$^{38}$

Como foram muitos os desvios até atingirem esse ponto, o ouvidor mandou aos louvados que subissem ao alto de um morro vizinho de onde se encontravam para que pudessem traçar uma estimativa da distância até o Pelourinho, a exemplo do recurso utilizado nas outras partes da medição. Feito o exame, os oficiais resolveram abater 6 cordas na medição, ficando somadas nove cordas. Seguiram com a medição "até junto as casas de Raymundo Pinto aonde se completaram vinte e três cordas", ${ }^{39}$ ali abateram mais 3 cordas pelos desvios estimados.

Os oficiais continuaram pela mesma estrada para completar as trinta cordas e, chegando ao ponto onde se dava as 10 cordas restantes, estimaram que

deviam medir mais duas cordas para completar verdadeiramente a dita medição, e medindo se as mesmo pela dita estrada adiante acabou a última junta a huma rocha na mesma estrada pela parte de cima.90

No dia seguinte, 20 de janeiro, partiram os oficiais para a quarta parte da medição. A direção a ser tomada era o Morro do Itacolomim (sic) e do caminho que levava aos Mainartes, tomando o rumo de "su-sueste" (sic).

Saindo com efeito a dita medição pela Rua que sai para o Largo do Chafariz, continuou por ele fora para a parte da Olaria, e seguindo a mesma estrada com a voltas dela se entrou a subir para o Morro do Itacolomim ate hum alto no meio dele aonde ele dito Doutor Juiz do Tombo mandou parar com a medição e aos louvados que examinassem as voltas que o caminho tinha dado lançando uma linha estimativa daquele sitio ao Pelourinho que estava a vista. ${ }^{41}$

A essa altura, somavam 19 cordas e os oficiais estimaram que deveriam abater 3 cordas e meia, totalizando quinze 15 cordas e meia. Continuando pela estrada a subida do morro, completaram no alto o total de 27 cordas e meia e, por ser possível avistar o Pelourinho deste ponto, o ouvidor mandou que os oficiais avaliassem melhor os desvios feitos. Outras 2 cordas e meia foram retiradas, ficando em 25 braças na tal paragem. As 5 cordas restantes deram

\footnotetext{
${ }^{38}$ Idem, f. 23v-24.

${ }^{39}$ Idem, f. $24 \mathrm{v}$.

${ }^{40}$ Idem, f. 25.

${ }^{41}$ Idem, f. 26.
} 
em hum sitio junto a hum monte de pedras grandes que se acham na mesma estrada e volta que ela foi a descer para um regato que esta junto ao primeiro rancho que se acha na mesma estrada e por completar neste sitio a dita meia légua que se media. ${ }^{42}$

A quinta parte da medição se iniciaria em 21 de janeiro de 1752, "correndo para o morro da Passagem e capela de Santo Antônio, seguindo o rumo [de nor] sudueste." ${ }^{43}$ Ao contrário dos outros dias, nessa empreitada não haviam casas ou outros obstáculos que os impedissem de seguir o rumo escolhido. Assim, da praça a medição

desceu o córrego, e atravessando o mesmo se subiu morro acima a buscar o caminho que vai para Vila Rica e seguindo o mesmo caminho ate se completarem seis cordas se desviou a mesma medição para a parte do caminho que vai para o sítio do Capitão Manoel Cardoso Cruz buscando-se o rumo que se levava e seguindo se o mesmo se foram atravessando com a dita medição aquelas terras até o alto em que se acha hum [tanque] dito Capitão Manoel Cardoso aonde se completaram onze cordas. ${ }^{44}$

Desse ponto os oficiais desceram pelo despenhadeiro, atravessaram o "córrego ou rio que vem de Vila Rica" ${ }^{45}$ e dali seguiram

subindo a dita medição pelo Morro acima e lavras que neles se acham até com efeito entrar no dito Arraial e Morro da Passagem, e continuando a mesma medição por entre as casas dele foi seguindo até o mais alto morro e ponta em que acaba em alguma distância por detrás da Igreja de Santo Antônio daquele Arraial em cujo sitio sem completaram vinte e cinco cordas. ${ }^{46}$

Sendo possível avistar o Pelourinho da cidade, o ouvidor mandou que os seus oficiais estimassem o abatimento que deveriam fazer, os quais retiraram 4 cordas do total. Medidas, então, as 21 cordas, o ouvidor achou por bem interromper ali o processo pelas dificuldades que se impunha para continuar por ser o terreno todo "percepitado (sic) e inculto". ${ }^{47}$

Bastante meticuloso em seus processos administrativos, o ouvidor mandou que o porteiro do Senado que tomasse nota para que, a qualquer momento que fosse necessário, pudessem continuar dali a medição da parte que faltava. Aos moradores da região caberia reconhecer não apenas a parte

\footnotetext{
${ }^{42}$ Idem, f. 27-27v.

${ }^{43}$ Idem, f. 28.

${ }^{44}$ Idem, f. 28-28v.

${ }^{45}$ Idem, f. $28 \mathrm{v}$.

${ }^{46}$ Idem.

${ }^{47}$ Idem, f. 29.
} 
já feita, mas também aquela que ficara por fazer para completar de fato a meia légua da sesmaria naquela distância.

Para outra parte da medição, os oficiais escolheram o rumo do Sul e saíram diretamente pela recém ocupada Rua Nova, que dava pouca diferença nessa direção. Contudo, não puderam seguir este rumo "pela fragosidade dos montes e algum mato que serviria de grande embaraço."48 Optaram por repetir o caminho feito para a parte do Morro do Itacolomim, no rumo de "[su-sueste]" ${ }_{49}$ (sic) com maior comodidade para buscar a direção e paragem que almejavam. Dessa forma,

saindo com efeito a dita medição pela praça em que se acha o chafariz foi seguindo o caminho da Olaria ate o principio da subida do Itacolomy, aonde apartando-se para a parte direita e atravessando hum pequeno córrego que ali se achava foi seguindo sempre pela estrada acima até ao sítio de Manoel Dias, aonde se completaram dezoito cordas. ${ }^{50}$

Os louvados retiraram 4 cordas, ficando o total até esse local em 14 cordas. Seguiram "pela mesma estrada acima até o alto da Serra donde passa o mesmo caminho e desce para o sitio do Sibrão e Varja no qual sítio se completaram vinte e oito 28 cordas." ${ }^{51}$ A mando do ouvidor, abateram-se outras 6 cordas, resultando no alto dessa paragem a medição 22 cordas, perfazendo o total de 1100 braças.

De volta ao Pelourinho na manhã de 22 de janeiro de 1752, os oficiais partiram para a sétima e última parte da medição. Em direção ao Arraial da Passagem, saíram pelo "rumo Sudueste [quartel] de oeste" e, como para esta parte também não havia casas ao redor da praça que os obstruísse, desceram até o córrego e depois subiram o morro para buscar o caminho que seguia para Vila Rica, onde a medição continuou "até que se chegou a hum alto de que se desce para a chapada." ${ }^{2}$

Nessa paragem, ao computo de 12 cordas, retiraram 2. Com 10 cordas somadas, os oficiais continuaram pela mesma estrada até o sítio de Domingos Rodrigues e Bento Lopes, onde completaram 15 cordas. Nesse local, de onde tinham uma melhor visão e era mais cômodo estimar a linha até o Pelourinho, o ouvidor solicitou que fizessem nova estimativa, e os oficiais

\footnotetext{
${ }^{48}$ Idem, f. 30.

${ }^{49}$ Idem.

${ }^{50}$ Idem, f. 30-30v.

${ }^{51}$ Idem, f. 31.

${ }^{52}$ Idem, f. 32v.
} 
acordaram retirar outras 2 cordas, ficando o total, até ali, de 13 cordas. A medição continuara dali pela mesma

estrada adiante desviando-se neste lugar por hum atalho da mão direita que
desce pelo pasto abaixo até entrar outra vez na mesma estrada pela qual
foi continuando, e atravessando a ponte ao sair dela subiu logo para cima e
correndo por entre as casas foi buscando o caminho que vai para Vila Rica
e [?] junto ao muro de Domingos Soares e neste sitio por ser levantado e se
devisar (sic) dele a paragem em que se tinha feito o abatimento mandou ele
dito Doutor Juiz do Tombo se parasse com a mesma medição que até aqui se
completavam vinte e quatro cordas..$^{53}$

Feito novo abatimento solicitado por Costa Matoso, o total ali era de 22 cordas. Pela estrada que levava até Vila Rica, os oficiais prosseguiram até completar as 30 cordas junto ao muro de um cercado, propriedade de Manoel Alves Cabral, ponto em que se encerrava a demarcação da sesmaria da câmara de Mariana em 1752.

\section{Apontamentos finais: dinâmica e materialidade da posse das terras}

O método levado a cabo para delimitação das terras da sesmaria da câmara de Mariana foi bastante similar entre as medições de 1719 e 1752, utilizando o pelourinho como centro geográfico e correndo meia légua para cada uma das direções escolhidas. O procedimento em si e os percalços enfrentados, sobretudo pelos oficiais envolvidos na medição de 1752, deixam evidentes as transformações ocorridas na estrutura urbana da cidade neste ínterim.

A medição feita em 1719 quase não encontrou obstáculos, tais como montanhas, casas, rios e córregos - ao menos é o que se percebe no relato dos medidores - que impedissem seu prosseguimento. Escolhidos os rumos - noroeste, nordeste, sudeste e sudoeste - partiram os medidores até chegarem ao total de mil e quinhentas braças.

Não se quer afirmar aqui que essas dificuldades não tenham existido para esses homens, contudo, os maiores detalhes fornecidos pela equipe do ouvidor Costa Matoso revelam uma maior preocupação com as estruturas formativas do espaço urbano. Como hipótese, pode-se pensar que o crescimento da "malha urbana" de Vila do Carmo/Mariana tenha exigido maior rigor dos medidores, no intuito de estabelecerem com maior clareza as balizas das terras pertencentes à câmara.

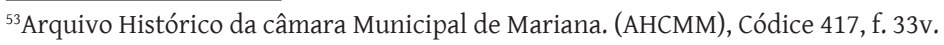


No caso da demarcação feita em 1752, esse maior rigor fica evidente na escolha dos rumos a serem tomados que são seis: "nor-noroeste", "norte com pouca diferença para a parte da quarta, do Noroeste", "nordeste", "su-sueste" (sic), "sul","sudueste [quarta] de oeste" ${ }^{54}$; dois a mais do que os quatros rumos escolhidos em 1719, embora essa medição de 1752 traga, ainda, sete balizas demarcatórias, se repetindo o rumo seguido de "sudueste quarta de oeste" que ia dar no arraial da Passagem, onde dois marcos foram postos. Os rumos que apontam são também bastante precisos, como "nor-noroeste" e "sudueste [quarta] de oeste", todos eles ditados por uma bússola - ou agulhão.

Outra consideração a ser feita é sobre os inúmeros descontos na medição que Costa Matoso sugere aos seus medidores, algo que não aparece nas medições de 1719. O intuito pode ter sido o de não prejudicar os domínios fundiários da câmara por todos os desvios que a maioria das medições exigiu devido aos novos edifícios da cidade ou à topografia do terreno.

Outro aspecto importante diz respeito às referências citadas pela equipe do ouvidor Costa Matoso em comparação com aquelas citadas pelos medidores de 1719. Se, por um lado, os medidores do começo do século XVIII usaram as propriedades e seus proprietários, evidenciando a instabilidade dessas referências, por outro, a equipe do ouvidor Costa Matoso já se utiliza de marcos bem mais estáveis, como os caminhos que levam para os outros povoados, localidades da cidade que já recebiam denominação de acordo com capelas construídas, como a capela de Sant'Anna, os Monsus, ou mesmo o então nomeado Morro do Itacolomim para estabelecer com maior clareza a direção que sua medição tomava.

Nesse aspecto, é notável que o auto de demarcação de 1719 já trouxesse expressões como "estrada chamada Itacolomim" ou "arraial chamado da Passaje" (sic), ${ }^{55}$ evidenciando que as estruturas que nomeariam geograficamente o espaço circunvizinho ao núcleo urbano da Vila do Carmo ainda estavam em incipiente processo de formação. Mais considerável ainda é notar que o vocábulo "chamado", em referência ao arraial de Passagem, é suprimido na cópia da demarcação de 1719 feita a mando do ouvidor Costa Matoso para os Livros do Tombo de $1752 .{ }^{56}$

\footnotetext{
${ }^{54}$ Idem, f. 18; 21v; 23v; 26; 30; 32v.

${ }^{55}$ ACSM, f. 202-202v.

56 “ (...) se completou no Arraial da Passagem estrada geral de Vila Rica (...).”AHCMM, f. 12v.
} 
Contudo, o aspecto que mais chama atenção são os marcos colocados em cada uma das balizas, as quais dizem respeito à materialidade da posse sobre o terreno e as transformações na ocupação do território de Minas Gerais. Ou seja, ainda que o ritual de posse continuasse o mesmo, o ouvidor Caetano da Costa Matoso mandava colocar "marco de pedra para divisa e clareza do futuro". ${ }^{57}$

Ainda que não possamos ter certeza sobre o material que fora utilizado na confecção dos marcos postos em 1719, na primeira medição da sesmaria da Câmara, a partir desse pedido do ouvidor, é possível inferir que eles tivessem se deteriorado até o ano de 1752. Dessa forma, a utilização de um material perene como a pedra pode ser representativa de uma mudança no aspecto da materialidade da posse daquelas terras: na tentativa de superar a transitoriedade e incipiência dos primeiros arraiais, uma vez mais os oficiais envolvidos no tombo da sesmaria de Mariana buscavam afirmar a "permanência" da povoação. ${ }^{58}$

Assim como os oficiais da câmara fizeram em 1719, em cada um dos pontos onde a medição se encerrava o ouvidor mandara o procurador da câmara, que acompanhava o trabalho, lançar os atos possessórios de "quebrar ramos e lançar terra ao ar" ${ }^{59}$ Seguindo os rituais, os marcos seriam colocados ficando com 5 palmos fora da terra.

Ademais, no marco estaria também inscritas as letras iniciais de "Sesmaria da câmara da cidade Mariana", evidenciando a mudança de status na hierarquia dos lugares do Império Português. Ao passar, em 1745, de Vila

\footnotetext{
${ }^{57}$ Idem, f. 2v.

58 "Aceitar o sítio dos arraiais significou aceitar, portanto, além de aspectos do modo de vida que se pretendia manter - ainda que adiante "regulado" e "sujeito às leis da justiça" -, também as primeiras ocupações ditas "espontâneas" já realizadas pelos moradores, igualmente sujeitas, a partir de então, a regulações de ordem e requisições de decência. Modo de vida e acomodação urbana, não por acaso referidos aqui conjuntamente, passaram a se orientar por regulações proporcionadas à dignidade hierárquica da povoação, motivadas pelas conveniências metropolitanas e temperadas pelas conveniências populares. A partir de então, uma nova disposição de permanência, por assim dizer oficialmente inventada e instaurada, deveria levar a um gradativo incremento das primeiras construções existentes - as "habitaçõesinhas provisórias" -, exigindo, além de uma necessária adequação de estruturas construídas, o "aumento" da dignidade aparente das construções e do próprio ambiente urbano das povoações, objetivo presente durante toda a primeira metade do século XVIII. Observaremos em vários documentos e contextos um duplo sentido para o termo "aumento", ambos diretamente relacionados ao nosso estudo das intervenções urbanas setecentistas: "aumento" como incremento quantitativo - expansão física -, e também qualitativo - incremento de dignidade." In: BASTOS, Rodrigo de Almeida. A arte do urbanismo conveniente: o decoro na implantação de novas povoações em Minas Gerais na primeira metade do século XVIII. Dissertação (Mestrado em Arquitetura e Urbanismo) Faculdade de Arquitetura, Universidade Federal de Minas Gerais, Belo Horizonte, 2003. p. 72-73.
}

${ }^{59}$ AHCMM, f. 21v; 23; 25-25v; 27v; 29; 31v; 34v. 
do Carmo à cidade de Mariana para sediar o bispado, os marcos limítrofes de suas terras traziam agora a inscrição que indicavam a propriedade da própria câmara sobre o terreno. Diferentemente dos marcos postos em 1719 que traziam a inscrição REY, tendo inscrito nos marcos de 1752 as iniciais que indicava sua propriedade sobre a terra onde estava a cidade, a câmara cumpria também com a demanda da Igreja Católica de apenas aceitar que seus bispos se instalassem em terras consideradas livres, fora, ao menos em teoria, de um senhorio régio.

Por fim, aponta-se que esse processo de demarcação constituiu uma ampliação, ou uma readequação, dos domínios da câmara, passando a incluir povoados mais afastados do centro da cidade, como o Morro Santana, que não aparece citado na medição feita em 1719. Incluídos nas terras da câmara, os moradores desses povoados se viram obrigados a contribuir como pagamento de foros. Como bem colocou Claudia Damasceno Fonseca, a demarcação de terras mais distantes do centro mostra como um fator de ordem fiscal poderia contribuir para alterar - e ainda adequar - os limites da jurisdição da câmara, com o intuito de arrecadar maiores receitas. ${ }^{60}$ Além disso, é possível captar variados aspectos que estariam por trás das posses de terrenos conquistados pelos portugueses e toda a gama de relações que acabavam envolvidas nessas posses.

A população, por sua vez, nem sempre aceitou passivamente mais um tributo imposto pela coroa lusitana. Seus protestos, questionamentos e insatisfações também tiveram espaço nas anotações meticulosas do ouvidor Costa Matoso. Esses questionamentos, entretanto, são assunto para outro artigo.

Artigo recebido para publicação em 04/12/2012

Artigo aprovado para publicação em 27/05/2013

\footnotetext{
60 "Notemos, primeiramente, que algumas povoações que, até então, haviam sido consideradas como arraiais do termo de Mariana - ou seja, localidades separadas do ponto de vista físico, embora submetidas à câmara da cidade - são designadas no auto de medição como arrebaldes ou subúrbios da cidade episcopal. É o caso dos arraiais de Morro de Santana e da Passagem, situados a cerca de três quilômetros (meia légua) da sede. Ao serem incluídos nos limites da sesmaria, seus moradores se viram obrigados ao pagamento dos foros. Percebe-se, assim, que um fato de ordem fiscal podia ampliar os limites da cidade e relativizar as distâncias - pelo menos no espírito das autoridades locais." FONSECA,op. cit., p. 494.
} 